\title{
Limited Functional Health Literacy, Health Information Sources, and Health Behavior among Community-Dwelling Older Adults in Japan
}

\author{
Yuko Yoshida, ${ }^{1}$ Hajime Iwasa, ${ }^{2}$ Shu Kumagai, ${ }^{3}$ Takao Suzuki, $^{4}$ and Hideyo Yoshida $^{1}$ \\ ${ }^{1}$ Tokyo Metropolitan Institute of Gerontology, 35-2 Sakae-cho, Itabashi-ku, Tokyo 173-0015, Japan \\ ${ }^{2}$ Fukushima Medical University School of Medicine, 1 Hikarigaoka, Fukushima City, Fukushima 960-1295, Japan \\ ${ }^{3}$ University of Human Arts and Sciences, 1288 Magome, Iwatsuki-ku, Saitama City, Saitama 339-8539, Japan \\ ${ }^{4}$ National Center for Geriatrics and Gerontology, 35 Gengo, Morioka-machi, Obu City, Aichi 474-8511, Japan
}

Correspondence should be addressed to Yuko Yoshida; yossy@tmig.or.jp

Received 11 December 2013; Accepted 29 January 2014; Published 6 March 2014

Academic Editors: A. T. Isik, J. C. Nitz, and W. Qidwai

Copyright (C) 2014 Yuko Yoshida et al. This is an open access article distributed under the Creative Commons Attribution License, which permits unrestricted use, distribution, and reproduction in any medium, provided the original work is properly cited.

\begin{abstract}
The objectives of this study were to explore how health information sources vary by functional health literacy levels and the relationship between health literacy and health behaviors among the old-old, community-dwelling adults. A cross-sectional study was used. The sample included 620 participants from a rural community in northern Japan. We used structured questionnaires to gather demographic information and assess health-related behaviors, information sources utilized, and functional health literacy. Functional health literacy scores were categorized into three groups, namely, low, middle, and high literacy. Individuals with limited health literacy were more likely to drink less alcohol, were less physically active, had less dietary variety, and had a low rate of medical check-ups. They were also less likely to use printed media, organization or medical procedure, electronic media, and accessed fewer health-related information sources. This study highlights the necessity of information tools that facilitate better access to information among older adults with limited health literacy.
\end{abstract}

\section{Introduction}

Limited health literacy is a barrier to adequate health care. Health literacy is defined as "the degree to which individuals have the capacity to obtain, process, and understand basic health information and services needed to make appropriate health decisions" [1]. People with limited health literacy typically have a poor understanding of their medical condition and medical prescriptions, as well as poorer disease management, making it difficult for them to make good decisions regarding various aspects of their health [2].

Limited health literacy among older adults is a major concern because it has implications for their overall health. Previous research has shown a limited health literacy rate of around 24\% [3-5] among community-dwelling older adults. Therefore, in the interests of community service, it is important to consider ways of providing health information to older adults who have limited health literacy.
Previous studies have shown that limited health literacy is independently associated with a poorer health status, inclusive of physical and mental health [4], as well as mortality [6-9]. Older adults with limited health literacy have a poor understanding of health-related information [10] and tend to have limited access to health care services $[3,11]$. Thus, health care access may act as a mediator between limited health literacy and poor health status among older adults. Furthermore, varying health literacy levels may contribute to disparities in health status among older adults [3].

Improvements in health literacy could facilitate better healthcare decision-making and lead to better health and quality of life in later life [2]. In order to do this, better methods of providing health information to older adults with limited health literacy are needed. To devise such methods, it would be important to clarify the medical backgrounds of these older adults as well as their typical mode of accessing health information. 
Older adults are often given information in written form in various contexts, including private and public health care services. Municipalities and hospitals commonly use mail, pamphlets, leaflets, and hard-copy hospital bills to provide health information to older adults - thus, this method can be considered as the typical mode of initially providing health information to older adults. However, because functional health literacy is markedly lower among older adults [12], written forms of health information may be inappropriate for this population, as they may fail to access it. As such, we saw a need to determine the extent to which older adults are able to understand this health-related information.

Thus, the purpose of this study was to assess the characteristics associated with limited health literacy and to give an indication of what health information sources are typically used by older, community-dwelling adults; furthermore, we aimed to see how health information sources differ by functional health literacy level and whether health literacy affects health behavior. Results from this study would enable the development of measures for enhancing access to health information among older adults with limited health literacy.

\section{Methods}

2.1. Study Setting and Participants. The target population of this study consisted of older adults living in a rural area in northern Japan. This is a predominantly agricultural region. In 2011, 969 older adults aged 74 and above were registered as residents in certain administrative district. Of these, 729 (279 men and 450 women) agreed to participate (response rate: $75.2 \%$ ); of the 240 that did not participate, 207 declined participation, 22 were hospitalized, and 11 had died by the time of data collection. One hundred and nine of 729 participants gave no responses on the functional health literacy scale. Thus, the final study sample included 620 adults ( 244 men and 376 women; Mage $=80.7$ years, $\mathrm{SD}=4.9$ ) who completely filled out the functional health literacy scale.

This study was approved by the Ethics Committee of the Tokyo Metropolitan Institute of Gerontology. Participants gave written informed consent to participate in the study.

2.2. Measurements. Volunteers distributed the questionnaire for completion by participants. The questionnaire contained items assessing demographic information, including sex, age, education, and living arrangements (alone, with a spouse, or living with family, such as children or relatives). Further, the questionnaire evaluated participants' health-related behavior, including their activities of daily living (ADL; i.e., the ability to walk long distances alone), smoking habits, alcohol consumption, regular physical activity, dietary variety, whether they undergo regular medical check-ups, and sources of health information.

The health information sources were also examined in more detail, and participants could provide multiple answers. Available information sources included people (family and friends), organizations/medical procedure (medical institution such as hospital or clinic, medical check-ups, complete medical check-ups, health consultation service, community organization, and community senior club), electronic media (television, radio, video/DVD, and Internet), printed media (newspapers, books/magazines, public newsletters, and circular notices), "other", and "none."

The frequency of physical activity was determined through a structured interview questionnaire. Participants were required to indicate whether they engaged in physical activity (yes or no), as well as the frequency thereof per week (5-6 days per week, 2-4 days per week, one day or less per week). During the interviews, physical activity was defined as any type of activity that increased bodily movement (e.g., calisthenics, going for walks, gate-ball, jogging, tennis, golf, hiking, dancing, swimming, and martial arts).

Dietary variety was determined through a dietary variety score $[13,14]$ consisting of 10 food categories (meat, fish and shellfish, eggs, milk, soybean products, potatoes, green or orange vegetables, fruits, seaweed, and fats, and oils). One point was given for consumption of an item from each food category every day throughout one week. Thus, the dietary variety score for one week for each individual ranged from 0 to 10 , with a higher-end score indicating greater dietary variety.

Functional health literacy was assessed using a single five-item scale [15]. These items were adopted from a health literacy scale with three subscales: functional (5 items), communicative (5 items), and critical (4 items). The functional health literacy scale was developed to assess the level of difficulty experienced when reading instructions or leaflets from the hospital. Each of the five items was rated on a 4point scale, from 1 (never) to 4 (often). For each participant, the scores were averaged and reversed accordingly, such that a higher average score indicated higher functional health literacy. Participants were categorized into three groups depending on the tertile (low: 1 2.2; middle; 2.3 3.0; and high: 3.1 4.0) of the health literacy score.

2.3. Statistical Analyses. We used chi-square tests to analyze categorical variables, while analysis of variance (ANOVA) was used to compare continuous variables (i.e., demographic characteristics, health information sources, and health behaviors) across the three health literacy levels (i.e., low, middle, and high).

We used IBM SPSS statistical software, Version 20.0 for Windows (SPSS, Inc., Chicago, IL) for all analyses, with statistical significance set at $P<.05$.

\section{Results}

The mean (SD) age was 80.3 (4.6) years for men and 80.9 (5.1) for women. The majority of the sample was female, at $60.6 \%$, while $9.4 \%$ of all participants were living alone and $69.2 \%$ could go out alone. The mean health literacy score was significantly higher in men than women $(M=2.9, \mathrm{SD}=0.8$ versus $M=2.5, \mathrm{SD}=0.9, P<.001)$.

The distribution of the response rate and the mean score for each item on the functional health literacy score is shown in Table 1. Cronbach's alpha coefficient for all five items on the 
TABLE 1: Distribution of responses and mean scores on the functional health literacy scale $(n=620)$.

\begin{tabular}{|c|c|c|c|c|c|}
\hline \multirow{2}{*}{$\begin{array}{l}\text { While reading instructions or leaflets } \\
\text { from hospitals/pharmacies, you... }\end{array}$} & \multicolumn{4}{|c|}{ Number (\%) } & \multirow{2}{*}{ Means \pm SD } \\
\hline & Never & Seldom & Sometime & Often & \\
\hline Found the print too small to read & $182(29.4)$ & $196(31.6)$ & $155(25.0)$ & $87(14.0)$ & $2.76 \pm 1.02$ \\
\hline $\begin{array}{l}\text { Found characters and words that you did } \\
\text { not know }\end{array}$ & $112(18.1)$ & $185(29.8)$ & $235(37.9)$ & $88(14.2)$ & $2.52 \pm 0.95$ \\
\hline Found that the content was too difficult & $114(18.4)$ & $197(31.8)$ & $215(34.7)$ & $94(15.2)$ & $2.53 \pm 0.96$ \\
\hline $\begin{array}{l}\text { Needed a long time to read and } \\
\text { understand }\end{array}$ & 114 (18.4) & $219(35.3)$ & $188(30.3)$ & 99 (16.0) & $2.56 \pm 0.97$ \\
\hline Needed someone to help you read & $274(44.2)$ & $132(21.3)$ & $144(23.2)$ & $70(11.3)$ & $2.98 \pm 1.06$ \\
\hline Total score on the five items & & & & & $2.67 \pm 0.86$ \\
\hline
\end{tabular}

functional health literacy scale was 0.94 . The distribution of the total scores is shown in Figure 1.

We observed significant differences in health literacy levels by demographic characteristics. Participants with low health literacy were more likely to be female $(P<.001)$ and older $(P<.01)$ and have lower levels of education $(P<.001)$ and lower ADL $(P<.001)$; furthermore, they were more likely to live with living with family $(P<.05)$.

Participants with low health literacy scores drank less alcohol $(P<.05)$, were less physical active $(P<.001)$, had less dietary variety $(P<.001)$, and had a low rate of medical check-ups $(P<.001$; see Table 2$)$.

The most commonly cited sources of health information for the overall sample were television (85.6\%), newspapers (57.1\%), doctors/health professionals (51.1\%), family $(40.5 \%)$, friends and acquaintances $(38.8 \%)$, and medical check-ups (37.2\%). Participants with low health literacy scores were less likely to use medical check-ups $(P<.01)$, health consultations/health class $(P<.001)$, community senior clubs $(P<$ $.05)$, several forms of electrical media (television, $P<.01$ ), and several forms of printed media (book/magazine, $P<$ .001 ; newspaper, $P<.001$; public newsletter, $P<.001)$.

The mean (SD) number of information sources was 3.6 (2.4) for low, 4.9 (2.8) for middle, and 5.0 (2.9) for high literacy levels, respectively $(P<.001)$.

\section{Discussion}

To address current concerns about the appropriateness of the manner in which health information is disseminated to older adults, we assessed how health information sources varied by functional health literacy level in community-dwelling older adults and examined the relationship between limited health literacy and health-related behaviors (Table 3). We observed significant differences in the type and amount of health information sources according to participants' health literacy levels. Furthermore, limited health literacy was associated with equally limited preventive health behaviors, such as less physical activity and dietary variety, as well as low frequency of medical check-ups.

Results showed that people of all health literacy levels used other people as a source, including family, friends, or doctors. In contrast, older adults with limited health literacy were less likely to use printed media, organizations,

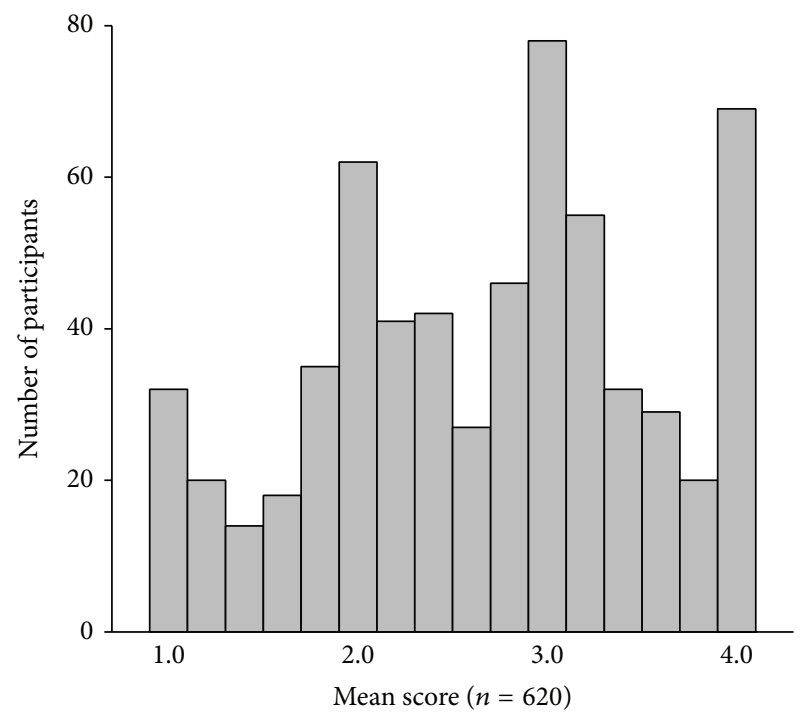

FIgURE 1: Distribution of functional health literacy score of all participants in this study.

or medical procedures as information sources. Furthermore, older adults with limited health literacy had lower ADL and lived with their children or other relatives. It might be that these individuals have difficulties participating in community events, such as community gatherings. Further, they do not typically obtain information in written form voluntarily; rather they involuntarily obtain information from family members.

Previous studies have shown that the number of information sources was not significantly associated with functional health literacy scores among patients with diabetes [15]. Our findings showed that a decrease in the number of information sources was associated with a decline in functional health literacy. In addition, individuals with higher literacy levels used different types of media to access health information. Nevertheless, the difference between the results of the study by Ishikawa et al. [15] and those from the current study could be due to differences in the study samples.

Older adults with inadequate health literacy (e.g., difficulty in reading health information) may fail to gain access to important information in various contexts, such as 
TABLE 2: Demographic and lifestyle characteristics by health literacy level.

\begin{tabular}{|c|c|c|c|c|c|}
\hline \multirow{2}{*}{ Characteristic } & \multirow{2}{*}{ Overall $(n=620)$} & \multicolumn{3}{|c|}{ Functional health literacy } & \\
\hline & & Low; $1 \sim 2.2(n=222)$ & Middle; $2.3 \sim 3.0(n=193)$ & High; 3.1 4.0 $(n=205)$ & \\
\hline Gender (women; \%) & $376(60.6)$ & $159(71.6)$ & $111(57.5)$ & $106(51.7)$ & $* * *$ \\
\hline Age $($ mean $\pm \mathrm{SD})$ & $80.7 \pm 4.9$ & $81.6 \pm 5.3$ & $80.1 \pm 4.5$ & $80.1 \pm 4.6$ & $* *$ \\
\hline Education ( $\geq$ high school; \%) & $114(19.2)$ & $21(10)$ & $38(20.5)$ & $55(27.8)$ & $* * *$ \\
\hline Living arrangements (\%) & & & & & * \\
\hline Alone & $57(9.4)$ & $22(10.2)$ & $18(9.4)$ & $17(8.4)$ & \\
\hline Spouse & $99(16.3)$ & $22(10.2)$ & $32(16.8)$ & $45(22.3)$ & \\
\hline Living with family & $453(74.4)$ & $172(79.6)$ & $141(73.8)$ & $140(69.3)$ & \\
\hline Total ADL (going out alone; \%) & $420(69.2)$ & $107(48.9)$ & $183(75.9)$ & $130(88.4)$ & $* * *$ \\
\hline Drinking habits (current; \%) & $163(26.5)$ & $44(19.9)$ & $61(31.9)$ & $58(28.4)$ & * \\
\hline Smoking habits (current; \%) & $27(4.4)$ & $10(4.5)$ & $10(5.2)$ & $7(3.4)$ & ns \\
\hline Physical activity (active; \%) & $231(37.7)$ & $60(27.1)$ & $73(38.4)$ & $98(48.5)$ & $* * *$ \\
\hline Dietary variety score $(\geq 5 ; \%)$ & $230(39)$ & $65(30.7)$ & $64(35.2)$ & $101(51.5)$ & $* * *$ \\
\hline Medical check-up (attended; \%) & $360(58.1)$ & $96(43.2)$ & $120(62.2)$ & $144(70.2)$ & $* * *$ \\
\hline
\end{tabular}

Note. Data are $n$ (\%) or means \pm SD. ${ }^{*} P<.05,{ }^{* *} P<.01,{ }^{* * *} P<.001$. There are missing values on some items.

ADL: activities of daily living.

$\chi^{2}$ was used for categorical variables and one-way analysis of variance was used for continuous variables.

TABLE 3: Health information sources and number thereof by health literacy level.

\begin{tabular}{|c|c|c|c|c|c|}
\hline & Overall $(n=620)$ & & Functional health literacy & & \\
\hline & & Low; $1 \sim 2.2(n=222)$ & Middle; $2.3 \sim 3.0(n=193)$ & High; 3.1 4.0 $(n=205)$ & \\
\hline People & & & & & \\
\hline Family & $250(40.5)$ & $102(46.2)$ & $68(35.2)$ & $80(39.2)$ & ns \\
\hline Friend & $240(38.8)$ & $89(40.3)$ & $77(39.9)$ & $74(36.3)$ & ns \\
\hline Organization/medical procedure & & & & & \\
\hline Medical institution & $316(51.1)$ & $105(47.5)$ & $111(57.5)$ & $100(49.0)$ & ns \\
\hline Medical check-up ${ }^{\#}$ & $230(37.2)$ & $62(28.1)$ & $84(43.5)$ & $84(41.2)$ & $* *$ \\
\hline Complete medical check-up ${ }^{\#}$ & $23(3.7)$ & $3(1.4)$ & $9(4.7)$ & $11(5.4)$ & - \\
\hline Health consultation service & $108(17.5)$ & $20(9.0)$ & $46(23.8)$ & $42(20.6)$ & $* * *$ \\
\hline Community society & $30(4.9)$ & $6(2.7)$ & $12(6.2)$ & $12(5.9)$ & ns \\
\hline Community senior club & $111(18.0)$ & $27(12.2)$ & $41(21.2)$ & $43(21.1)$ & * \\
\hline Electronic media & & & & & \\
\hline Television & $529(85.6)$ & $180(81.4)$ & $161(83.4)$ & $188(92.2)$ & $* *$ \\
\hline Radio & $76(12.3)$ & $23(10.4)$ & $27(14.0)$ & $26(12.7)$ & ns \\
\hline Video/DVD & $5(0.8)$ & $0(0.0)$ & $1(0.5)$ & $4(2.0)$ & - \\
\hline Internet & $6(1.0)$ & $0(0.0)$ & $4(2.1)$ & $2(1.0)$ & - \\
\hline Printed media & & & & & \\
\hline Book/magazine & $168(27.2)$ & $23(10.4)$ & $59(30.6)$ & $86(42.2)$ & $* * *$ \\
\hline Newspaper & $353(57.1)$ & $83(37.6)$ & $123(63.7)$ & $147(72.1)$ & $* * *$ \\
\hline Public newsletter & $168(27.2)$ & $39(17.6)$ & $61(31.6)$ & $68(33.3)$ & $* * *$ \\
\hline Circular notice & $151(24.4)$ & $43(19.5)$ & $52(26.9)$ & $56(27.5)$ & ns \\
\hline Other & $5(0.8)$ & $1(0.5)$ & $1(0.5)$ & $3(1.5)$ & - \\
\hline None & $10(1.6)$ & $10(4.5)$ & $0(0.0)$ & $0(0.0)$ & - \\
\hline Number of sources & $4.7 \pm 2.8$ & $3.6 \pm 2.4$ & $4.9 \pm 2.8$ & $5.0 \pm 2.9$ & $* * *$ \\
\hline
\end{tabular}

Data are $n(\%)$ or means $\pm \mathrm{SD}$. There are missing values on some items. ${ }^{*} P<.05,{ }^{* *} P<.01,{ }^{* * *} P<.001$.

$\chi^{2}$ was used for categorical variables, while analysis of variance (ANOVA) was used for continuous variables.

The number of sources was calculated using the ANOVA with the post hoc least significant difference test. The low functional health literacy group used less information sources than the middle $(P<.001)$ and high $(P<.001)$ functional health literacy groups.

- Not examined due to too few responses.

"A "medical check-up" refers to health-care services typically provided by a health insurance organization (in public health service), while a "complete medical check-up" is provided by private hospitals that operate in private practice. 
interacting with health care service providers $[3,11]$. However, the results from the current study showed that older adults with limited health literacy do not typically obtain health information from printed media. Thus, these individuals could fail to access health information provided in written form. Although written information is a predominant mode of information communication for older adults in public health care settings, older adults with limited health literacy would have difficulty in accessing relevant information. This is compounded by the fact that these individuals used fewer information sources than did those with adequate health literacy. Therefore, there is a need to develop more ways of disseminating health-related information to the target population in a suitable manner.

Previous studies have shown that limited health literacy among individuals is associated with less frequent participation in physical activities [16] and lower likelihood of performing frequent, vigorous physical activity [7]. In line with this, our findings showed that low levels of functional health literacy were associated with less physical activity. Limited health literacy was also associated with less dietary variety; similarly, previous studies have shown that limited health literacy was associated with lower fruit and vegetable consumption [17].

The above findings suggest that individuals with low health literacy would find it difficult to engage in appropriate health care management. Healthier lifestyles choices such as regular physical activity and comprehensive dietary habits are important factors in the maintenance of health status in old age. Some studies have also shown that physical activity is inversely associated with all-cause mortality in older men and women and that there are benefits from even low levels of activity [18]. Diet quality was also significantly associated with all-cause mortality in older adults aged 65 and over [19]. Furthermore, the cited study showed that combinations of diet and lifestyle factors, including physical activity, were associated with all-cause and cause-specific mortality in older adults [20] and that physical activity and the intake of fruits and vegetables are independently and jointly related to longevity in older women [21]. Therefore, individuals with limited health literacy tend to lead poorer lifestyles, which could induce functional and mental decline.

Previous studies have shown that limited health literacy is associated with poor access to health care, inclusive of primary care, preventive services, and medication [3]. Another study showed that inadequate health literacy is independently associated with lower use of preventive health care services among individuals enrolled in Medicare, who are aged between 65 and 79 years old [11]. The current study supported this finding, as it showed that limited health literacy among older adults coincided with less frequent medical check-ups. It is common to receive a notice for a medical check-up in written form in Japan; this information would be inaccessible to older adults with limited health literacy.

Many studies have shown that education plays a considerable role in literacy levels; however, nearly all of the participants in this study had undergone mandatory education, which facilitates basic literacy levels. Therefore, the limited health literacy levels were due to reasons other than simply being unable to read the information on the most basic level.

In sum, limited health literacy may hamper older adults' ability to benefit from information relating to health care. In turn, this could result in poorer health outcomes among such individuals.

\section{Limitations}

Several limitations were identified in the current study. First, this study used a cross-sectional design, which does not allude to any causal relationship between health literacy and preventive health behavior. In addition, previous studies have shown that general cognitive performance affects health literacy [5]. The current study did not include any analysis of the participants' cognitive functioning. In addition, the study excluded disabled older adults, inclusive of those suffering from cognitive decline, or those requiring nursing care. There is a need for further research on the long-term effects of health literacy on health behavior; these could further be explored in relation to cognitive functioning.

\section{Conclusion}

We explored how health information sources differed by functional health literacy levels and sought to determine the relationship between limited health literacy and health behavior among rural, community-dwelling older adults. Older adults with limited health literacy were less likely to use printed media and accessed fewer health information sources. Furthermore, limited health literacy was associated with less engagement in preventive health behavior.

Older adults with limited health literacy need to modify their lifestyles to ensure better health outcomes. It is evident that the dissemination of health information in written form is unsuitable for many people, particularly older adults with low functional literacy. Thus, better information tools are necessary to enable older adults with limited health literacy to access health information.

\section{Conflict of Interests}

The authors declare that there is no conflict of interests regarding the publication of this paper.

\section{Acknowledgments}

The authors are grateful to the participants and the municipal employees and other staff members for cooperation in this study. This work was supported by Research Funding for Longevity Sciences (23-33) from the National Center for Geriatrics and Gerontology (NCGG), Japan, a grant from the Tokyo Metropolitan Institute of Gerontology, and a Grant-inAid for Scientific Research C (no. 24590835).

\section{References}

[1] C. R. Selden, M. Zorn, S. Ratzant, and R. M. Parker, "Current Bibliographies in Medicine 2000-1," Health Literacy, 2000, http://www.nlm.nih.gov/pubs/cbm/hliteracy.html . 
[2] B. D. James, P. A. Boyle, J. S. Bennett, and D. A. Bennett, "The impact of health and financial literacy on decision making in community-based older adults," Gerontology, vol. 58, no. 6, pp. 531-539, 2012.

[3] R. L. Sudore, K. M. Mehta, E. M. Simonsick et al., "Limited literacy in older people and disparities in health and healthcare access," Journal of the American Geriatrics Society, vol. 54, no. 5, pp. 770-776, 2006.

[4] M. S. Wolf, J. A. Gazmararian, and D. W. Baker, "Health literacy and functional health status among older adults," Archives of Internal Medicine, vol. 165, no. 17, pp. 1946-1952, 2005.

[5] A. D. Federman, M. Sano, M. S. Wolf, A. L. Siu, and E. A. Halm, "Health literacy and cognitive performance in older adults," Journal of the American Geriatrics Society, vol. 57, no. 8, pp. 1475-1480, 2009.

[6] D. W. Baker, M. S. Wolf, J. Feinglass, and J. A. Thompson, "Health literacy, cognitive abilities, and mortality among elderly persons," Journal of General Internal Medicine, vol. 23, no. 6, pp. 723-726, 2008.

[7] D. W. Baker, M. S. Wolf, J. Feinglass, J. A. Thompson, J. A. Gazmararian, and J. Huang, "Health literacy and mortality among elderly persons," Archives of Internal Medicine, vol. 167, no. 14, pp. 1503-1509, 2007.

[8] S. Bostock and A. Steptoe, "Association between low functional health literacy and mortality in older adults: longitudinal cohort study," BMJ, vol. 344, no. 7852, Article ID e1602, 2012.

[9] R. L. Sudore, K. Yaffe, S. Satterfield et al., "Limited literacy and mortality in the elderly: the health, aging, and body composition study," Journal of General Internal Medicine, vol. 21, no. 8, pp. 806-812, 2006.

[10] J. A. Gazmararian, D. W. Baker, M. V. Williams et al., "Health literacy among medicare enrollees in a managed care organization," Journal of the American Medical Association, vol. 281, no. 6, pp. 545-551, 1999.

[11] T. L. Scott, J. A. Gazmararian, M. V. Williams, and D. W. Baker, "Health literacy and preventive health care use among medicare enrollees in a managed care organization," Medical Care, vol. 40, no. 5, pp. 395-404, 2002.

[12] D. W. Baker, J. A. Gazmararian, J. Sudano, and M. Patterson, "The association between age and health literacy among elderly persons," The Journals of Gerontology B, vol. 55, supplement 6, pp. S368-S374, 2000.

[13] S. Kumagai, S. Watanabe, H. Shibata et al., "Effects of dietary variety on declines in high-level functional capacity in elderly people living in a community," Nippon Koshu Eisei Zasshi, vol. 50, no. 12, pp. 1117-1124, 2003.

[14] J. Kwon, T. Suzuki, S. Kumagai, S. Shinkai, and H. Yukawa, "Risk factors for dietary variety decline among Japanese elderly in a rural community: a 8-year follow-up study from TMIG-LISA," European Journal of Clinical Nutrition, vol. 60, no. 3, pp. 305-311, 2006.

[15] H. Ishikawa, T. Takeuchi, and E. Yano, "Measuring functional, communicative, and critical health literacy among diabetic patients," Diabetes Care, vol. 31, no. 5, pp. 874-879, 2008.

[16] J. S. Bennett, P. A. Boyle, B. D. James, and D. A. Bennett, "Correlates of health and financial literacy in older adults without dementia," BMC Geriatrics, vol. 12, p. 30, 2012.

[17] C. von Wagner, K. Knight, A. Steptoe, and J. Wardle, "Functional health literacy and health-promoting behaviour in a national sample of British adults," Journal of Epidemiology and Community Health, vol. 61, no. 12, pp. 1086-1090, 2007.
[18] W. J. Brown, D. McLaughlin, J. Leung et al., "Physical activity and all-cause mortality in older women and men," British Journal of Sports Medicine, vol. 46, no. 9, pp. 664-668, 2012.

[19] S. A. McNaughton, C. J. Bates, and G. D. Mishra, "Diet quality is associated with all-cause mortality in adults aged 65 years and older," Journal of Nutrition, vol. 142, no. 2, pp. 320-325, 2012.

[20] K. T. B. Knoops, L. C. de Groot, D. Kromhout et al., "Mediterranean diet, lifestyle factors, and 10-year mortality in elderly European men and women: the HALE project," Journal of the American Medical Association, vol. 292, no. 12, pp. 1433-1439, 2004.

[21] E. J. Nicklett, R. D. Semba, Q. L. Xue et al., "Fruit and vegetable intake, physical activity, and mortality in older communitydwelling women," Journal of the American Geriatrics Society, vol. 60 , no. 5, pp. 862-868, 2012. 


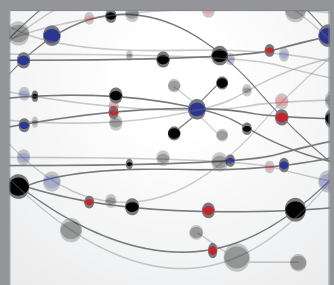

The Scientific World Journal
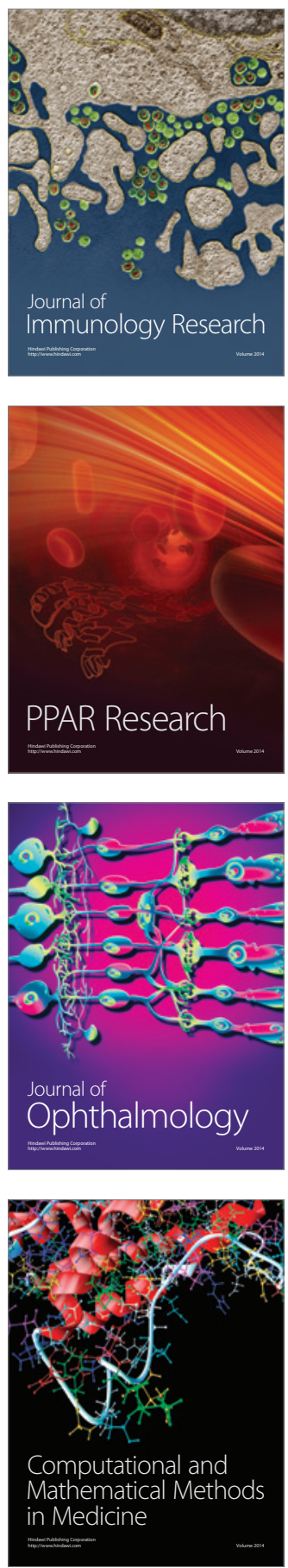

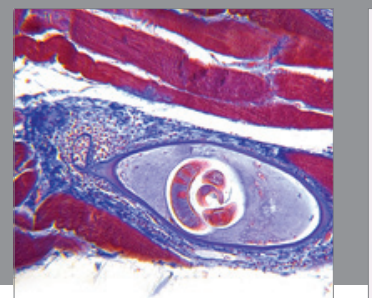

Gastroenterology

Research and Practice
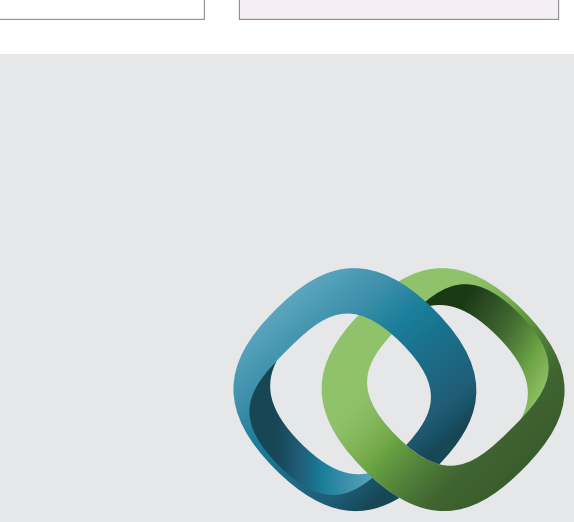

\section{Hindawi}

Submit your manuscripts at

http://www.hindawi.com
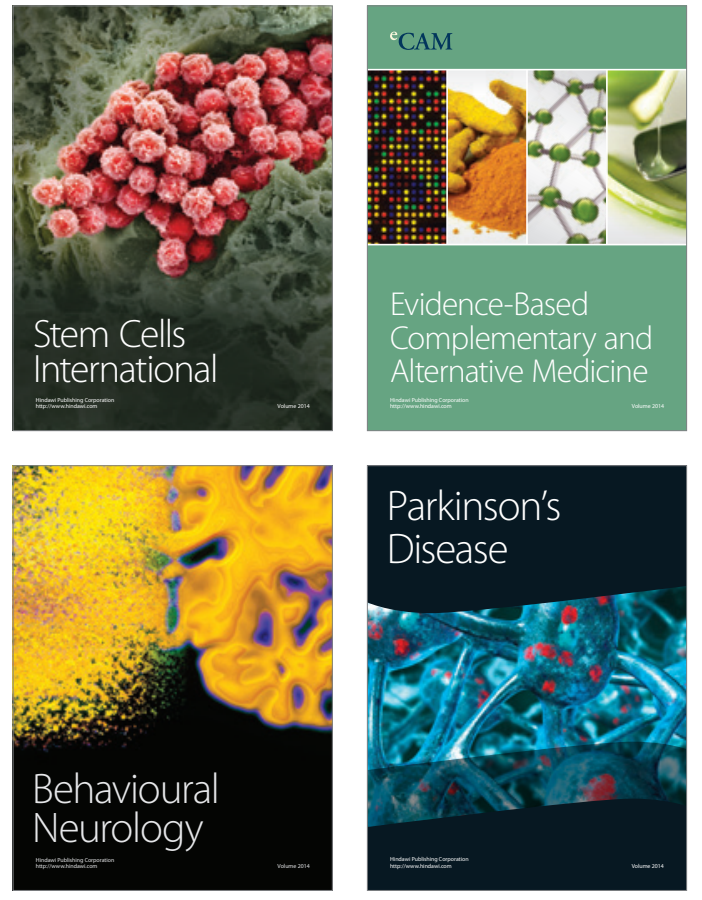
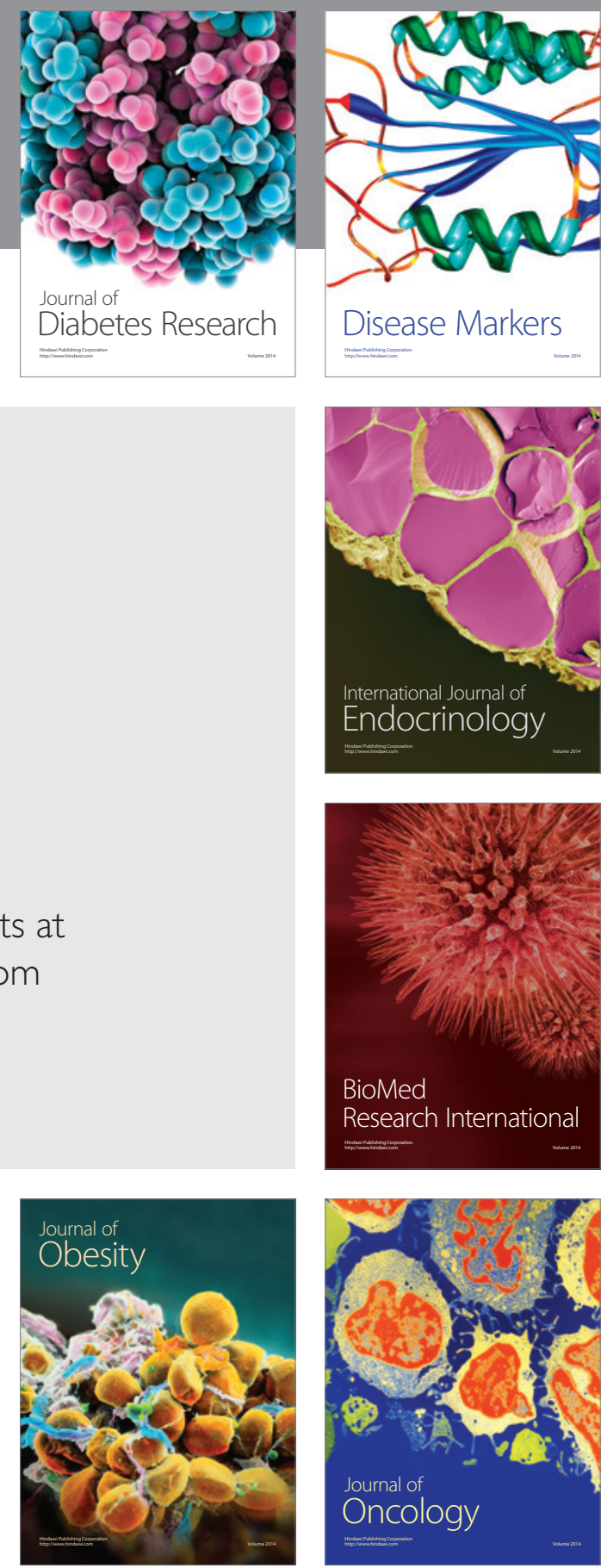

Disease Markers
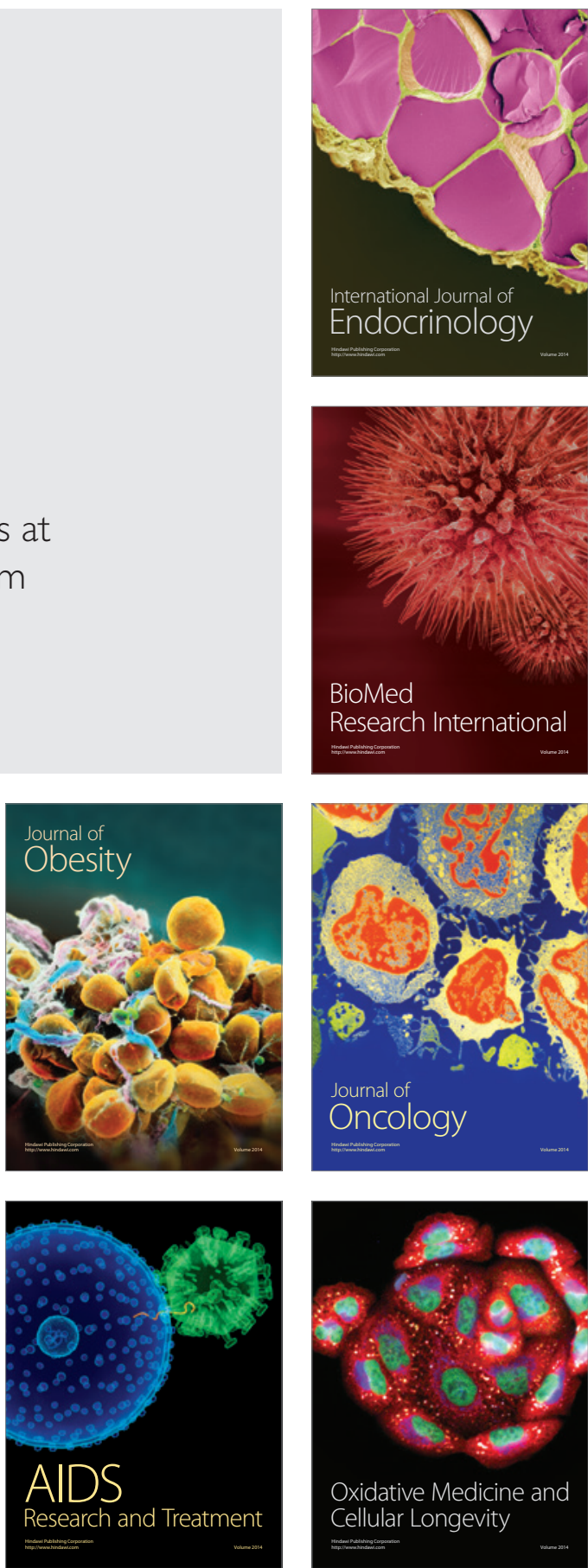